\title{
The Effect of Dynamic Local Self-Preheating in Laser Cladding on Grey Cast Iron
}

\author{
Peng Yi* - Pengyun Xu - Changfeng Fan - Chengkai Li - Yongjun Shi \\ China University of Petroleum, College of Mechanical and Electrical Engineering, China
}

In laser cladding, high cooling rates are accompanied by superior mechanical and metallurgical properties. However, these characteristics, along with the additive nature of the process, significantly contribute to the formation of thermal stresses, which are the main cause of any potential delamination and crack formation across the remelted area. To reduce thermal stress and better manage the microstructure, a strategy of dynamic local self-preheating has been designed. Laser-cladding experiments with no preheating, static global preheating, and dynamic local preheating with grey cast iron have been conducted. Parallel to the experimental investigations, numerical models have been established in order to study the temperature distributions and thermal stresses in different processes. The results indicate that dynamic local self-preheating contributes to reducing the transient thermal stress and residual stress compared with other methods. With self-preheating of the substrate, microstructures of the coarse-grained region are well-developed. The self-preheated sample reveals a more compact structure in the fusion area and can exhibit less cracking during the cladding process.

Keywords: laser cladding, grey cast iron, local self-preheating, numerical models, microstructure

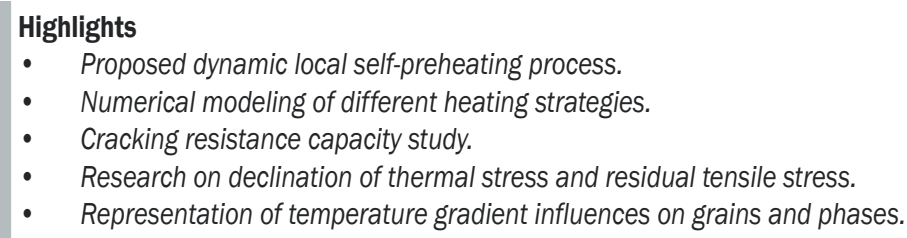

\section{INTRODUCTION}

Laser cladding, as one of advanced flexible surface manufacturing techniques, has shown great application potential in different fields, including coating modification, cladding of high-value components, and freeform fabricating. Compared to other conventional techniques, laser cladding has several advantageous technical characteristics, i.e. small heat-affected areas, minimal dilution and specific sizes for raw material procurement [1]. In this technique, a laser beam (as a heat source) strikes the upper surface of a substrate to form a small molten pool. By pre-placing or depositing metallic powder onto the upper surface, a narrow cladding tract is formed, and solid state transformation then occurs during the cooling process [2].

In spite of all the demonstrated advantages of the laser-cladding process, the substrates manufactured by this technique are prone to a number of drawbacks, including porosity, delamination and crack formation. Consequently, the process domain inherently undergoes a high cyclic heating and cooling regime. Many efforts have been made to improve the operating strategy to overcome these drawbacks. Jendrzejewski and Śliwiński [3] studied temperature and stress in the laser-cladding process of chromium steel; this research indicated that cracks in a single-layer coating decreased with preheating of the substrate. Danlos et al. [4] determined that laser ablation elevated the temperature of the substrate and that this is beneficial to suppress splashing in the thermal-spraying process. Amongst them, substrate preheating has been indicated to be a novel and important method, and can be expected to show better results. Many articles have implemented numerical and experimental approaches to investigate the effect of global substrate preheating in the laser-cladding process. The research of Zhang et al. [5] focused on the laser-cladding process of austenitic stainless steel; the experiments showed that preheating is necessary in order to prevent cracking. Aghasibeig and Fredriksson [6] investigated the laser-cladding process of an iron-based alloy on steel substrate; the results indicated that pre-heating the substrate reduced the number of cracks. Parallel to these, the feasibility of preheating on the reduction of microcracks has been demonstrated, and the susceptibility to micro-cracking is smaller for the preheated base. In these studies, the substrate was preheated globally in advance, i.e. static global preheating (SGP); the corresponding temperature field was then considered as an initial condition for the following analysis. The means of placing the work pieces in a furnace for an 
extended period as SGP process have been adopted widely but usually accompanied by low cladding efficiency and hostile working environments [7]. From another perspective, during the investigation concerned with the multilayer or overlapping cladding process, the effect of dynamic local preheating (DLP) from preceding tracks to a successive one should be considered, because they tend to increase the dilution of current cladding and improve the thermal stress status, as well as the metallurgical microstructure. Drawing inspiration from this, several research groups have developed different approaches to imitate the effect of DLP. For instance, in works from Zhou, the laser cladding was combined by simultaneously preheating the substrate with an induction heater (coil) (i.e. laser induction hybrid rapid cladding (LIHRC)), and the microstructure characteristics of the coating and interface were investigated [8]. As a result, the temperature gradient decreased, and the dilution of composite coating increased with the increase of the preheated temperature; moreover, the extent of metallurgical reaction can be controlled. This is an effective method of achieving the effect of DLP; however, it is accompanied by disadvantages, such as higher process cost and complexity because an entire set of removable induction heater devices (including the control operation) is additionally needed. Fallah et al. developed a laser DLP strategy, and conducted experimental and numerical measures to investigate the effects on the management of temperature and thermal stress distributions of Stellite 1 laser cladding powder on AISI-SAE 4340 alloy steel [9]. It was confirmed that a crack-free coating layer well-bonded to the substrate with a uniform dendritic structure and well-distributed deposited layer could be obtained. While multi-track and overlap scans made the DLP effects lack definition, the absence studies on the process parameters of a laser DLP strategy resulted in an incomplete investigation.

In this paper, single-track laser cladding experiments of different preheating strategies are conducted, and the microstructures are analysed. Numerical models are established to investigate the temperature and stress distribution under different preheating strategies. The effects of dynamic local preheating with different process parameters are shown.

\section{EXPERIMENTAL PART}

\subsection{Materials}

It is well known that the grey cast iron, as a prominent type of ferrous metal, is widely used in the manufacture of machine tool beds, cams, pistons, cylinders, etc., because of its low cost and desirable properties. Laser heat-treatment was successfully employed with cast iron to improve surface microstructures and harden machine parts in the research of Grum and Šturm [10] and [11]. However, few studies have reported research on the laser-cladding processes on grey cast iron since considerable free carbon, in the form of graphite flakes or globules, is present, and cladding on cast iron is difficult [12]. Therefore, for this work, a common grey cast iron, codenamed HT250, is selected as the substrate material. HT250 grey cast iron is denominated by Chinese Standard GB 943988. Commercial Fe-based powder, codenamed Fe311, is used as the cladding materials. The Fe 311 powdered alloy is one of the product lines of the Beijing General Research Institute of Mining \& Metallurgy. The powder size and density are approximately 150 to 250 $\mu \mathrm{m}$ and 2.8 to $4.8 \mathrm{~g} / \mathrm{cm}^{3}$, respectively. The chemical compositions of HT250 and Fe311 are given in Table 1.

Table 1. Chemical composition (wt. \%) of HT250 substrate and Fe311 powder

\begin{tabular}{lccccccccc}
\hline Material & $\mathrm{C}$ & $\mathrm{Si}$ & $\mathrm{Mn}$ & $\mathrm{P}$ & $\mathrm{S}$ & $\mathrm{Cr}$ & $\mathrm{Ni}$ & $\mathrm{B}$ & $\mathrm{Fe}$ \\
\hline HT250 & 3.250 & 1.570 & 0.920 & 0.060 & 0.059 & 0.270 & - & - & Bal. \\
\hline Fe311 & 0.100 & 1.000 & - & - & - & 15 & 10.000 & 1.000 & Bal. \\
\hline
\end{tabular}

Table 2. Processing parameters for different test cases

\begin{tabular}{|c|c|c|c|c|c|c|c|c|}
\hline Case No. & Strategy & $T_{0}\left[{ }^{\circ} \mathrm{C}\right]$ & $P_{p}[\mathrm{~W}]$ & $v_{p}[\mathrm{~mm} / \mathrm{min}]$ & $d_{p}[\mathrm{~mm}]$ & $P[\mathrm{~W}]$ & $v[\mathrm{~mm} / \mathrm{min}]$ & $d[\mathrm{~mm}]$ \\
\hline 1 & UNP & 22 & - & - & - & 2500 & 300 & 3.2 \\
\hline 2 & SGP & 350 & - & - & - & 2500 & 360 & 3.2 \\
\hline 3 & \multirow{3}{*}{ DLP } & \multirow{3}{*}{22} & 800 & 400 & \multirow{3}{*}{5.5} & \multirow{3}{*}{2500} & \multirow{3}{*}{360} & \multirow{3}{*}{3.2} \\
\hline 4 & & & 800 & 600 & & & & \\
\hline 5 & & & 600 & 600 & & & & \\
\hline
\end{tabular}


Samples of $50 \times 40 \times 10 \mathrm{~mm}$ are cut and mechanically surface polished. As shown in optical micrograph Fig. 1, the HT250 microstructure consists of A-type flaky graphite $(\mathrm{G})$ surrounded by lamellar pearlite $(\mathrm{P})$ and some amount of ferrite $(\mathrm{F})$.

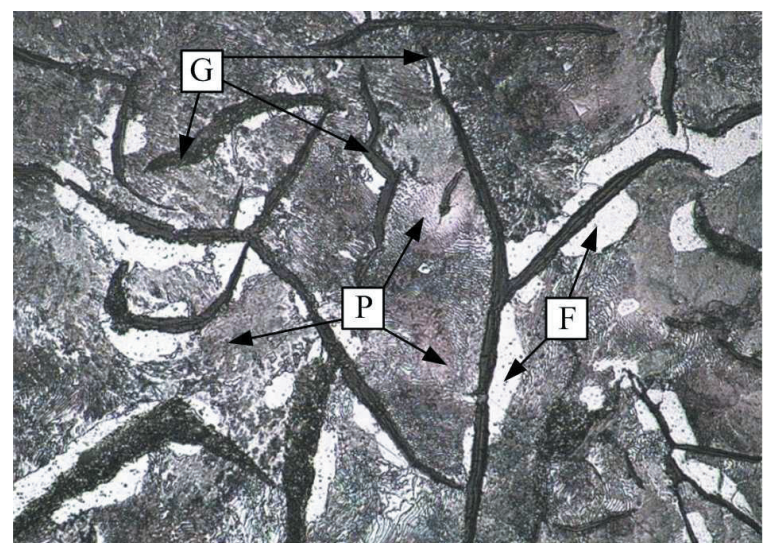

Fig. 1. Microstructure of HT250 grey cast iron

\subsection{Processing Conditions}

A single-track laser DLP strategy is designed and implemented to make the laser-cladding process more effective. Both the macro- and micro- characteristics of coating layers on substrates are processed by this DLP and traditional SGP methods, as well as on unpreheated (UNP) substrate. The process parameters are of vital importance for laser processing, and a great deal of research has been performed to determine the proper parameters to improve laser manufacturing quality [13] and [14]. Considering the lack of studies on the process parameters of the laser DLP strategy, different preheating laser power levels and scan rates are taken into account. To interpret the experimental results, coupled 3D time-dependent numerical models are employed to simulate the process along with the experimental analyses.

For the purpose of discussing the effects of the self-preheating process, six test cases are prepared, and the processing parameters are listed in Table 2. Firstly, numerical models for each case are established, and the results are comparatively analysed. Next, experiments are conducted for Cases 1 and 2 and complex ones for Cases 3 to 5. Furthermore, in the experimental process, three samples are taken to be fused for each case so as to avoid accidental events.In Table $2 T_{0}$ is the initial substrate temperature, $P, v$ and $d$ denote the laser power, scan rate and spot diameter, respectively, and the parameter with subscript $p$ represents the preheating condition.
For Cases 1 to 2, a conventional laser-cladding process without preheating and one with SGP in advance are conducted, respectively. With regard to Cases 3 to 5, laser claddings are separately prepared by using laser DLP with different parameters prior to the cladding process; the schematic is shown in Fig. 1. In DLP cases, cladding powders are always placed on substrates after the preheating process, with an approximate handling time of $40 \mathrm{~s}$ due to the processes of laying powders, raising the laser power and reducing the scan rate.

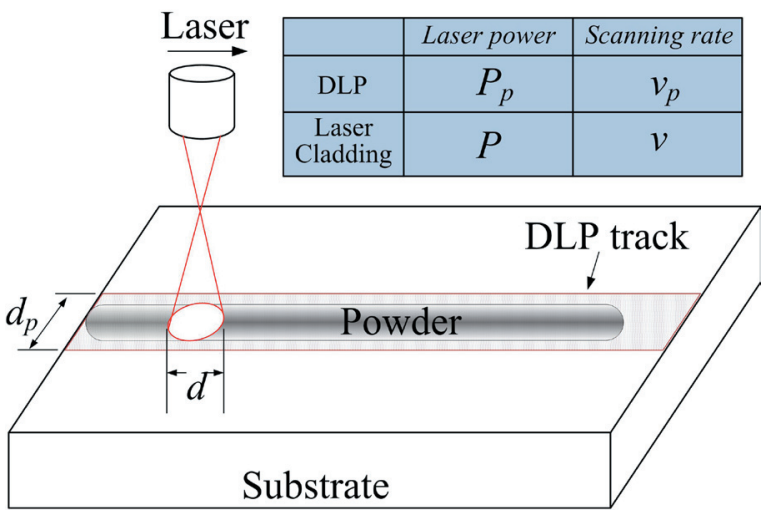

Fig. 2. Schematic diagram of the laser-cladding process with DLP in advance

In an experimental procedure, the substrates are cleaned with alcohol and then preset with the Fe311 powders on the surfaces. Laser cladding is carried out using a continuous wave $\mathrm{CO}_{2}$ laser (HL-10 type). Laser cladding experiments of UNP, SGP and DLP are performed in the course of the study to either verify or interpret the numerical outcomes. The metallographic samples are made with wire-electrode cutting, ground and polished, then etched in $4 \%$ Nital for 3 to 4 seconds, and blown dry after being flushed with pure alcohol. The microstructure and morphology are obtained via an MBA-1000 optical microscope.

\section{NUMERICAL PROCEDURE}

Since with laser cladding the temperature distribution and its evolution throughout the process determine the final mechanical and metallurgical qualities of the outcomes, to study and interpret the experimental results, a 3D numerical approach is developed using ANSYS commercial FEM code and employed to simulate the process [15]. In order to discretize the substrate, eight-node hexahedron elements are used. As shown in Fig. 3, for the appropriate result of a compromise between computing time and accuracy, 
a dense mesh is used around the fusion line, and a coarser mesh is adopted for the rest.

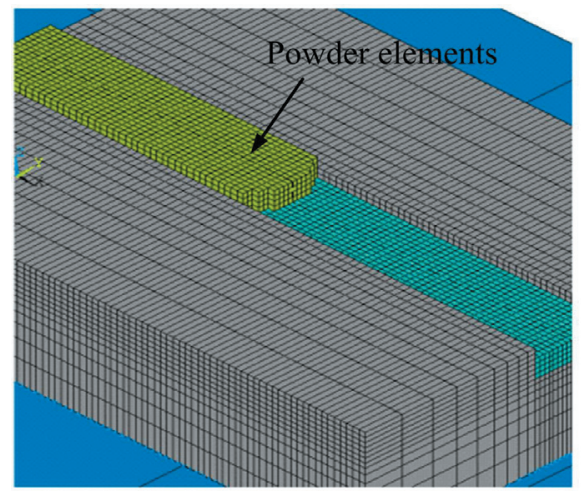

Fig. 3. FEM model with activation of powder elements

In this approach, a circular Gaussian $\mathrm{TEM}_{00}$ mode is considered for the laser energy distribution, as well as the effects of heat losses through convection and radiation, the latent heat of fusion, and the constraint forces are taken into account [16]. Meanwhile, a finite idle time between preheating and fabricating tracks is considered in the simulation, because it is inevitable in the experiments. For the numerical simulations, all process parameters and specifications are considered to be the same as those in experiments; then, by using this approach, time-dependent temperature and thermal stress fields across the process domain can be predicted. More details regarding the modelling process and its verification have been provided in previous work [17]. Consistent with the experiment process, numerical models (including processes of UNP, SGP and DLP) are established to investigate the effect of pre-heating. The time-dependent temperature, thermal stress and residual tensile stress in different processes are analysed.

In order to better analyse and interpret the effect of different pre-heating impacts, the microstructures of the samples need to be studied further. Therefore, experiments are carried out parallel with numerical models, and the microstructure morphology is analysed with OM.

\section{RESULTS}

\subsection{Numerical Results}

As the variation of the molten pool is extremely high and complex, it is difficult to accurately acquire data from this area. Meanwhile, thermal stress in the area at $0.5 \mathrm{~mm}$ under the molten pool is larger than that of other areas [9]. In order to investigate the timedependent maximum temperature and thermal stress variation, a path that is along the deposition direction and at $0.5 \mathrm{~mm}$ under the molten pool is selected.
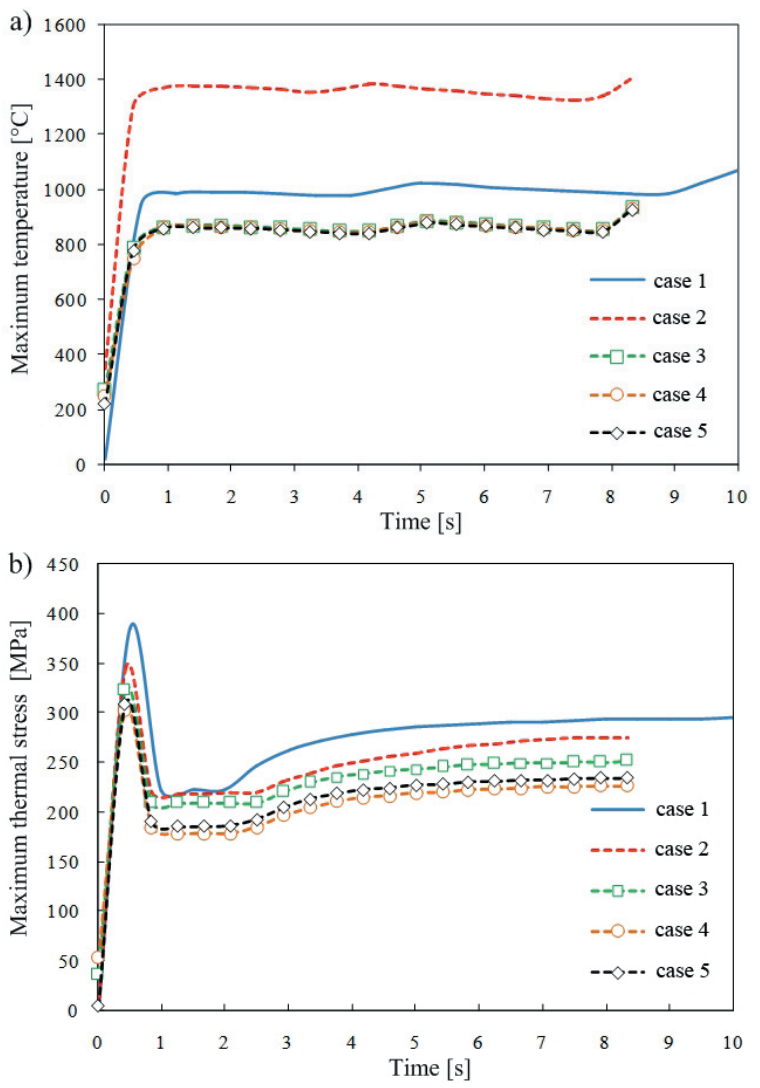

Fig. 4. a) Maximum temperature; and b) thermal stress of path along the deposition direction and at $0.5 \mathrm{~mm}$ under the molten pool in laser cladding in cases 1 to 5

Fig. 4 illustrates the maximum temperature and thermal stress variation of the path. The cladding time is 10 and $8.33 \mathrm{~s}$ in Case 1 and Cases 2 to 5 , respectively. As shown in Fig. 4a, the initial temperature of Case 1 is $22^{\circ} \mathrm{C}$ while Case 2 is $350^{\circ} \mathrm{C}$ as a result of global preheating before the cladding process. The initial temperatures of Cases 3 to 5 are $274,248,220{ }^{\circ} \mathrm{C}$, respectively, due to the different processing parameters of laser self-preheating. At the beginning of the laser-cladding process ( 0 to $0.8 \mathrm{~s}$ ), the temperature rises rapidly due to the sudden heat input. Next, the temperature remains steady and, during this period, the maximum temperature in Case 2 is the highest $\left(1350{ }^{\circ} \mathrm{C}\right)$, followed by Case $1\left(990^{\circ} \mathrm{C}\right)$ and Cases 3 to $5\left(870{ }^{\circ} \mathrm{C}\right)$.

Fig. $4 \mathrm{~b}$ shows the maximum thermal stress of the path in laser cladding. There is little thermal stress in Cases 1 and 2 at the beginning of cladding process, 
while the initial thermal stresses in Cases 3 to 5 are 39,47 and $6 \mathrm{MPa}$, respectively. When laser cladding is employed, there is a sharp increase of thermal stress in the initial period ( 0 to $0.8 \mathrm{~s}$ ), as shown in Fig. $4 \mathrm{~b}$. The thermal stress of Case 1 is the largest ( $385 \mathrm{MPa}$ ) followed by Case 2 (343 MPa) while DLP (Cases 3 to 5) indicates lower stresses: 322, 302 and $308 \mathrm{MPa}$, respectively. After the initial period, the laser-cladding process enters a stable period, and the temperature of the path remains constant. The maximum thermal stress declines by around $120 \mathrm{MPa}$ and then remains stable, as shown in Fig. $4 \mathrm{~b}$. In this period, the maximum thermal stress in Case 1 is the largest (290 MPa), followed by Case 2 (260 MPa). Thermal stresses in Cases 3 to 5 are smaller in comparison to Cases 1 and 2: 245, 220, $230 \mathrm{MPa}$, respectively.

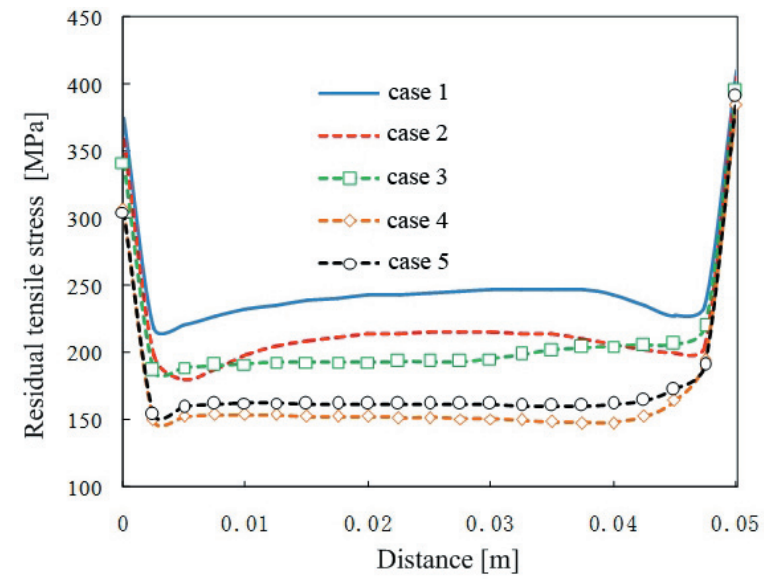

Fig. 5. Residual tensile stress of the path in the middle of the coating surface in cases 1 to 5

A path in the middle of the coating surface is selected to study the residual tensile stress, which has a vital impact on cladding quality. As shown in Fig. 5, residual tensile stress is very great at the ends of the coating, while maintaining a small and stable status in the middle. At the start of cladding layer $($ Distance $=$ $0 \mathrm{~m}$ ), the residual tensile stress of Case 1 ( $375 \mathrm{MPa}$ ) and Case $2(359 \mathrm{MPa})$ is larger than that of Cases 3 to $5(337,307,305 \mathrm{MPa}$, respectively). The residual stress decreases sharply by about $140 \mathrm{MPa}$ in the 0 to $0.0025 \mathrm{~m}$ distance. At the middle part of the coating (Distance $=0.0025$ to $0.048 \mathrm{~m}$ ), the residual tensile stress remains at a small and stable value. Case 1 is the largest (245 MPa) followed by Case 2 (215 MPa) and Case 3 (195 MPa). The residual tensile stresses in Cases 4 and 5 are small in comparison to others: 150 and $160 \mathrm{MPa}$ respectively. At the terminal of the coating $($ Distance $=0.048$ to $0.05 \mathrm{~m}$ ), the residual tensile stresses in Cases 1 to 5 have an acute increase, reaching $400 \mathrm{MPa}$.

\subsection{Microstructure Morphology Characteristics}

\subsubsection{Microstructure of UNP}

Fig. 6 shows a cross-section morphology for a sample of Case 1 without preheating (UNP). The overall morphology, cladding zone and fusion zone microstructure are illustrated in Fig 6 at high magnification. It is demonstrated that the overall cross section of the cladding zone is in a half-moon shape as a result of the uneven energy distribution of circular facula. The quality of the cladding zone is good, with a compacted microstructure and a low level of porosity. The depth of heat-affected zone is small, the maximum depth is approximately $450 \mu \mathrm{m}$ and the delamination of fusion zone is obvious.

As seen in Fig. 6b, the non-spontaneous nucleation process of the cladding zone is rapid due to the high cooling and temperature gradients. The formative column crystal has a refined structure with an average diameter of $9.6 \mu \mathrm{m}$ and is not highly directional due to the rapid crystal growth time. The microstructure of the fusion zone is shown in Fig. 6c. The top of the fusion zone is close to the cladding zone, and there is mutual fusion with elements in the cladding zone. This area consists of high amounts of lamellar cementite and some acicular martensite. In the middle of the fusion zone, there is a great deal of acicular martensite, residual austenite and partiallydissolved graphite. The bottom of the cladding zone consists of lamellar pearlite and acicular ferrite, as the heat effect is less than the top and middle area, and the transformation of materials is not obvious. In addition, the molten mass begins to transit with rapid supercooling below the eutectic temperature of $\mathrm{Fe}^{-} \mathrm{Fe}_{3} \mathrm{C}$. Meanwhile, cementite, a small amount of austenite and martensite form the hard eutectic phase.

\subsubsection{Microstructure of SGP}

Fig. 7 shows the cross section morphology for Case 2 (SGP, global preheating temperature of $350{ }^{\circ} \mathrm{C}$ ). It can be determined from Fig. 7a that the quality of the cladding zone is good, having a refined microstructure and a low level of porosity. The size of the cladding zone, the heat-affected zone and the fusion zone are all widened compared with Fig. 6a, owning to the preheating process prior to laser cladding. As shown in Fig. 7b, the average diameter of crystal is around $13.5 \mu \mathrm{m}$, which is obviously coarser than that of 

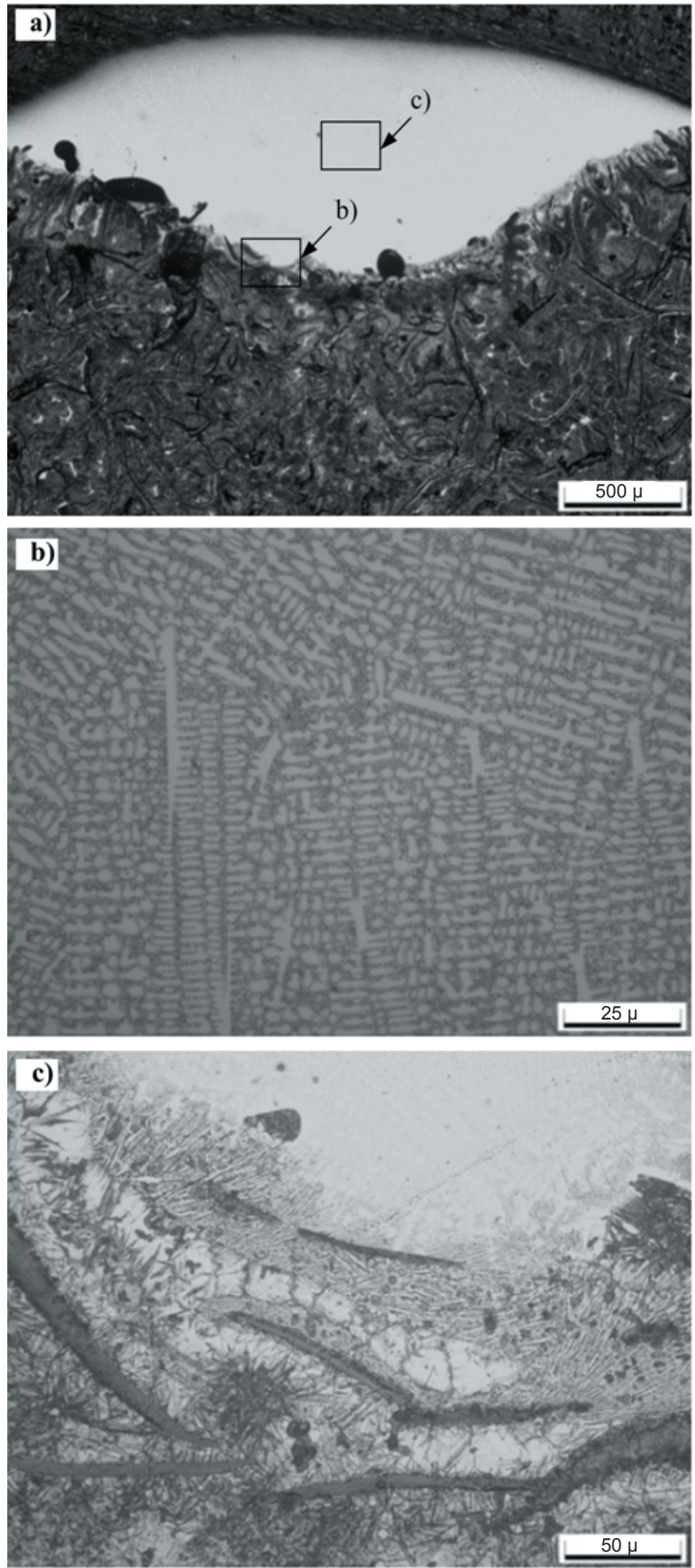

Fig. 6. Optical images of the clad cross section for case 1 sample in: a) overall section $(50 \times)$, b) cladding zone (500x), and c) fusion zone $(1000 x)$

Fig. $6 \mathrm{~b}$. As a result of the $350{ }^{\circ} \mathrm{C}$ global preheating process, the growth of crystals is better, and the secondary dendrite arms are stronger than that of UNP. Fig. 7c shows the microstructure of the fusion zone. It includes large amounts of lamellar cementite in the top and acicular martensite, residual austenite in the middle, which is similar to the microstructure
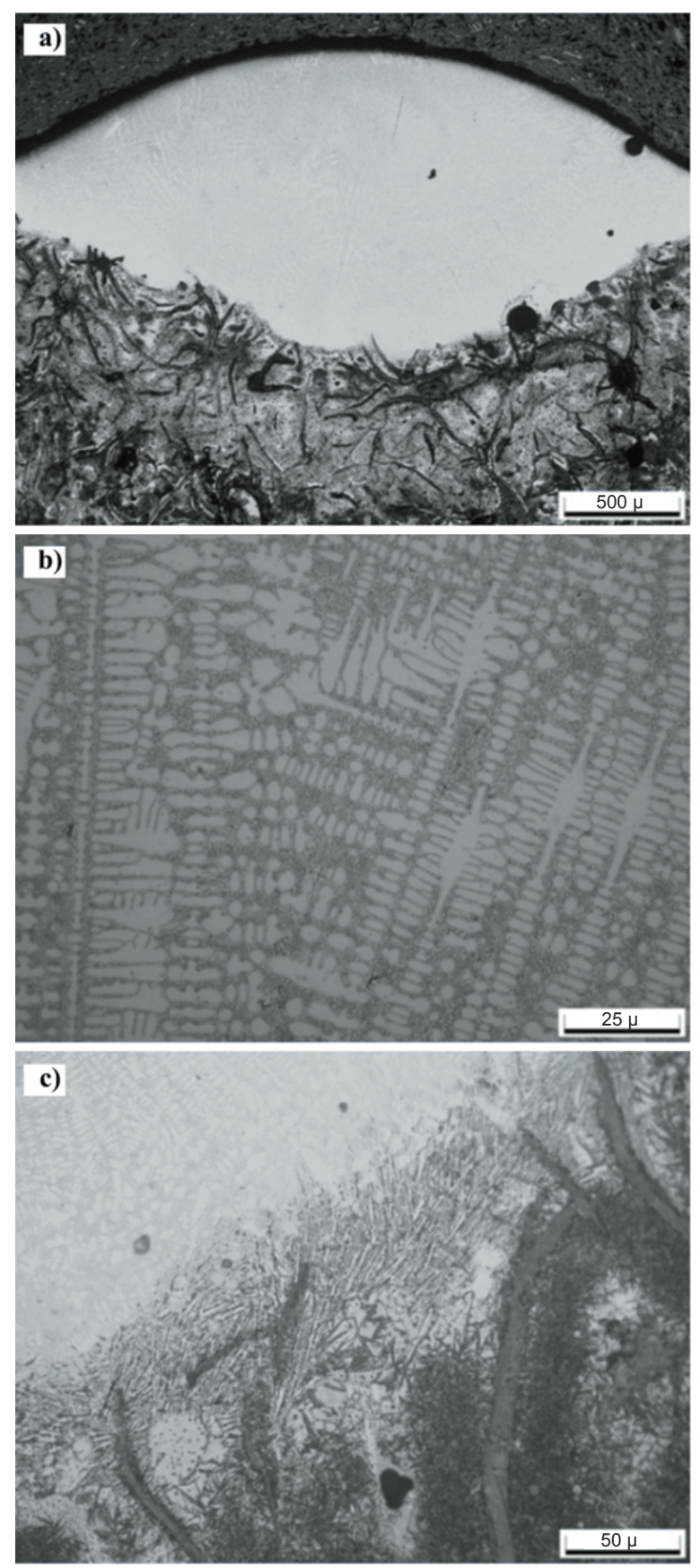

Fig. 7. Optical images of the clad cross section for case 2 sample in: a) overall section (50x), b) cladding zone (500x), and c) fusion zone (1000x)

distribution of UNP. However due to the decrease of the cooling rate and the degree of super-cooling, the proportions of cementite, martensite and bainite in the fusion zone decline, and the molten mass then begins to transit with the temperature above the eutectic temperature of $\mathrm{Fe}-\mathrm{Fe} 3 \mathrm{C}$ and below that of $\mathrm{Fe}-\mathrm{C}$. 
White iron structures are replaced by eutectic grey iron structures formed by graphite, austenite and martensite, inducing a decrease of micro-cracks and a decline of micro-hardness. Additionally, the graphite phase gathers in this zone, which mainly contains thick flake graphite with many branches, owning to the sufficient precipitation and rapid growth of graphite, which is not favourable for maintaining the structure integrity.

\subsubsection{Microstructure of DLP}

The microstructure morphology of the clad cross section for the Case 4 sample is illustrated in Fig. 8. The preheating temperature discipline is similar to the cladding process due to the same laser energy effect, which results in a small heat-affected zone, and the temperature descends to around $220{ }^{\circ} \mathrm{C}$ before cladding. Consequently, the maximum heataffected zone depth achieves about $530 \mu \mathrm{m}$ between that of UNP and SGP. Local self-preheating raises the temperature to the value between the eutectoid and eutectic points in terms of the iron-carbon phase diagram. The duration is around $0.7 \mathrm{~s}$, which leads to the primary cementite decomposition and ferrite growth because of the eutectoid phase transformation in surface microstructure. At this point, cladding is implemented, and the similarity of the molten mass is high, which induces a large amount of convection and a proliferation and decrease of local segregation. The substrate depth is influenced more obviously as a result of the direction of the laser thermal input. Similar to Fig. 7b, the degree of super-cooling is reduced by local preheating; the columnar crystals in the cladding zone with an average diameter around $11.8 \mu \mathrm{m}$ shown in Fig. $8 \mathrm{~b}$ are coarser than that demonstrated in Fig. 6b. As illustrated in Fig. 8c, the amount of cementite or other brittle organization in the fusion zone decreases more in comparison to SGP, while the ferrite increases, which results in a decline of micro-hardness.

\subsection{Hardness Distribution of Clad Area}

As seen in Fig. 9, the micro-hardness of the clad area under different preheating temperatures is examined from its surface to its bottom in a cross section along the depth direction. The hardness variation tendency of UNP, SGP and DLP is similar, which maintains a high hardness at the cladding zone and declines towards the substrate. The hardness of UNP is the highest, which reaches about $500 \mathrm{HV}$ at the top of the cladding zone, while the hardness of SGP is the
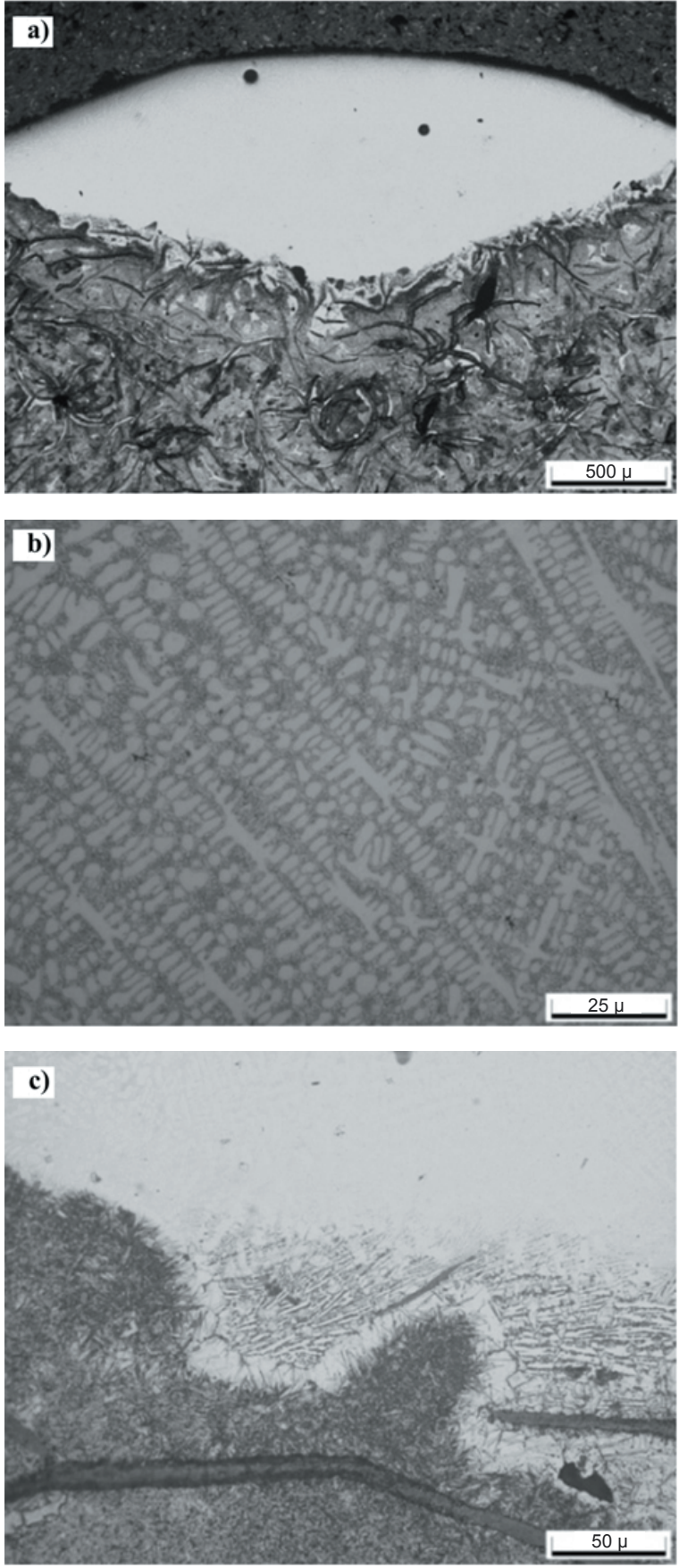

Fig. 8. Optical images of the clad cross section for Case 5 sample in: a) overall section (50x), b) cladding zone (500x), and c) fusion zone $(1000 \times)$

lowest (425 HV). The hardness of DLP is between that of UNP and SGP, which is around $475 \mathrm{HV}$. With the increase of distance away from the surface of the cladding zone, the hardness declines gradually. As the effect of laser heat input on the heat-affected zone and substrate is slight, the microstructure has little change. 
Therefore, the hardness of the heat-affected zone and the substrate area of UNP, SGP and DLP is quite close, at $230 \mathrm{HV}$.

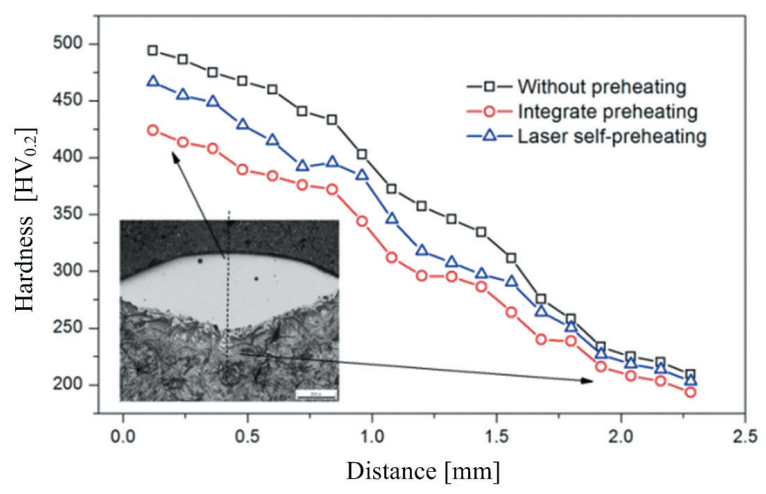

Fig. 9. Hardness distribution in cross section of the clad area

\section{DISCUSSION}

\subsection{Analysis of Numerical Models}

From the variation of maximum temperature and thermal stress (Fig. 4), it can be determined that, prior to laser-cladding process, the initial temperature for Cases 1 and 2 is $22{ }^{\circ} \mathrm{C}$ (ambient temperature) and $350{ }^{\circ} \mathrm{C}$ (SGP temperature), respectively. No thermal stress exists in Cases 1 and 2, as there is no external heat effect, and the substrates in Cases 1 and 2 achieve heat balance. For Cases 3 to 5, the substrates underwent a DLP process before cladding, so the initial temperature is higher than the ambient temperature, and there is a small amount of residual stress inside. When the laser-cladding process begins, substrates undergo a sudden massive heat input, and the temperature rises acutely in a short period ( 0 to $0.8 \mathrm{~s}$ ). The original stress balance is broken, and the material melts and deforms acutely, which induces a sharp increase of thermal stress at the beginning of the cladding process. Next, the cladding process enters a stable period, and the temperature of the path remains constant. As a result of the stable heat input, the maximum thermal stress declines and then remains stable. It is clearly indicated on Fig. $4 \mathrm{~b}$ that laser preheating is beneficial in reducing thermal stress. Cases 4 and 5 have the lowest stress (about $220 \mathrm{MPa}$ ), which is $70 \mathrm{MPa}$ lower than that of Case 1 and 34 $\mathrm{MPa}$ lower than that of Case 2. It can be summarized that DLP has a positive effect on reducing thermal stress, and that a relatively low preheating power is more suitable.

The residual tensile stress distribution in Fig. 5 demonstrates that without preheating (Case 1), the residual thermal stress is very great $(375 \mathrm{MPa}$ at ends and $240 \mathrm{MPa}$ at middle) and is highly likely to cause cracks. Cases 2 and 3 reveal a relatively lower stress than Case 1 , which is around $200 \mathrm{MPa}$ in the middle coating. As Case 3 has a high preheating power, and the temperature in the preheating process can reach $800{ }^{\circ} \mathrm{C}$, a great deal of stress appears and remains in the coating. Therefore, the accumulated stress is higher than that in Cases 4 and 5. Comparatively dynamic local preheating with low preheating power (Cases 4 and 5) indicates lower and uniform stresses, which are about $150 \mathrm{MPa}$ in the middle coating. It is concluded that residual tensile stress is reduced significantly by dynamic local preheating, due to the decline of temperature gradient and cooling rate. Case 4 exhibits a better performance than Case 5 does, as the preheating temperature is higher, and temperature gradient in Case 4 is smaller.

\subsection{Microstructure Changes}

From the overall section of microstructure in Cases 1, 2 and 5 , it can be determined that the quality of the cladding zone is good, containing compacted and refined microstructures and low porosity. The initial temperature of Case 1 is the lowest $\left(22{ }^{\circ} \mathrm{C}\right)$ as no preheating is applied, while the initial temperature of Case 2 is the highest $\left(350{ }^{\circ} \mathrm{C}\right)$ due to the SGP process. Case 5 undergoes the DLP process prior to laser cladding, and the initial temperature $\left(220^{\circ} \mathrm{C}\right)$ is between Cases 1 and 2. The high initial temperature increases the heat input in the laser-cladding process, and the sizes of the cladding zone, fusion zone and heat-affected zone are widened.

As no preheating is employed in Case 1, the convection time is extremely short, and the diffusion and penetration are incomplete. This results in a very low dilution rate and local composition aliquation of the fusion zone. However, the heat input increase in Case 2 contributes to the expansion of the molten pool and heat-affected area as a result of the constant laserspecific energy. Furthermore, the substrate can reach its melting point in less time, and the convection, diffusion and penetration of the molten mass are better, which result in more uniform composition and less local aliquation. The increasing initial temperature the reduces super-cooling degree and temperature gradient, and the nucleation rate in the molten pool decreases, which leads to better growth of crystals with clearer direction.

As for Case 5, the substrate has a dynamic laser preheating process, and the temperature increases to the point between eutectoid and eutectic. Therefore, 
the DLP process helps to decompose the primary cementite and improve the growth of ferrite. Due to the DLP process, the material has more similar characteristics with that in the laser-cladding process. The increase of the similarity of the molten mass improves the convection and proliferation, which dramatically decreases local aliquation.

\subsection{Hardness Variation}

It can be concluded that micro-hardness distributions are similar if one takes into consideration that in microstructure analysis the overall hardness gently declines after preheating. The hardness of testing points in the clad zone for UNP is highest, because no preheating is applied, and the microstructure after cladding includes many compact and refined grains and a great deal of hard phase. A sample of SGP is heated globally to $350{ }^{\circ} \mathrm{C}$ prior to the laser-cladding process, which results in a small super-cooling degree and temperature gradient. The nucleation rate declines and grains grow adequately. The microstructure of the clad area contains many coarse grains and phase with lower hardness, which induces the lowest hardness of the clad zone for SGP. The microstructure property of DLP is between that of UNP and SGP. The grain size of the cladding zone is larger than that of UNP but smaller than that of SGP. The convection and proliferation are better than that of UNP because of the laser preheating process, and the little hard phase. Therefore, the hardness of DLP is lower than that of UNP but higher than that of SGP.

\section{CONCLUSIONS}

(1) Different heating strategies, which include un-preheated substrate, SGP and DLP, are investigated in this work. Numerical models are established to study the effect of different preheating strategies and preheating parameters on temperature and stress variation. Experiments are employed to investigate the microstructure and micro-hardness. Compared with SGP in [6] and induction preheating in [8], laser DLP provides a flexible and reliable technology to reduce thermal stress and manage microstructure for laser cladding on grey cast iron.

(2) The numerical calculation proves that DLP elevates the initial temperature of the substrate before cladding. The temperature gradient, thermal stress and residual tensile stress decline in the laser-cladding process, which achieves highly consistent results with reference [9]. The analysis of different processing parameters indicates that laser power of $800 \mathrm{~W}$ and a scanning rate of 600 $\mathrm{mm} / \mathrm{min}$ is suitable for the dynamic preheating process.

(3) Laser DLP improves the convection and proliferation of the molten mass, which effectively helps to control the formation of the hard phase and contributes to the uniform microstructure in the cladding zone. Compared with the un-preheated substrate and static global preheating, laser dynamic local preheating has a more obvious effect on improving cracking resistance capacity.

(4) DLP reduces the super-cooling and temperature gradient, which induces coarse columnar grains and phase with lower hardness and brittleness. This causes the DLP sample to have lower microhardness than UNP, but the hardness is still higher than that of the substrate, which guarantees the integral hardness level.

\section{ACKNOWLEDGMENTS}

The paper was supported by the National Natural Science Fund of China (No. 51405512), the Science and Technology Development Project of Shandong Province (No. 2011GGX10329), the Science and Technology Fundamental Project of Qingdao City (No.13-1-4-255-jch) and the Fundamental Research Funds for the Central Universities (No. 13CX02076A).

\section{REFERENCES}

[1] Kim, Y.D., Kim, W.S. (2008). A numerical analysis of heat and fluid flow with a deformable curved free surface in a laser melting process. International Journal of Heat and Fluid Flow, vol. 29, no. 5, p. 1481-1493, Dol:10.1016/j. ijheatfluidflow.2008.06.009.

[2] Zhang, Y.M., Drake, R.P., Glimm, J. (2007). Numerical evaluation of the impact of laser preheat on interface structure and instability. Physics of Plasmas, vol. 14, no. 6, p. 62703, DOI:10.1063/1.2739453.

[3] Jendrzejewski, R., Śliwiński, G. (2007). Investigation of temperature and stress fields in laser cladded coatings. Applied Surface Science, vol. 254, no. 4, p. 921-925, DOI:10.1016/j.apsusc.2007.08.014.

[4] Danlos, Y., Costil, S., Liao, H., Coddet, C. (2008). Combining effects of ablation laser and laser preheating on metallic substrates before thermal spraying. Surface and Coatings Technology, vol. 202, no. 18, p. 4531-4537, Dol:10.1016/j. surfcoat.2008.04.038.

[5] Zhang, H., Shi, Y., Kutsuna, M., Xu, G.J. (2010). Laser cladding of Colmonoy 6 powder on AISI316L austenitic stainless steel. 
Nuclear Engineering and Design, vol. 240, no. 10, p. 2691 2696, D0I:10.1016/J.nucengdes.2010.05.040.

[6] Aghasibeig, M., Fredriksson, H. (2012). Laser cladding of a featureless iron-based alloy. Surface and Coatings Technology, vol. 209, p. 32-37, D0l:10.1016/j.surfcoat.2012.08.013.

[7] Alimardani, M., Toyserkani, E., Huissoon, J.P., Paul, C.P. (2009). On the delamination and crack formation in a thin wall fabricated using laser solid freeform fabrication process: An experimental-numerical investigation. Optics and Lasers in Engineering, vol. 47, no. 11, p. 1160-1168, D0l:10.1016/j. optlaseng.2009.06.010.

[8] Zhou, S.F., Dai, X.Q. (2010). Microstructure evolution of Febased WC composite coating prepared by laser induction hybrid rapid cladding. Applied Surface Science, vol. 256, no. 24, p. 7395-7399, D0l:10.1016/j.apsusc.2010.05.079.

[9] Fallah, V., Alimardani, M., Stephen, F.C., Khajepour, A. (2010). Impact of localized surface preheating on the microstructure and crack formation in laser direct deposition of Stellite 1 on AISI 4340 steel. Applied Surface Science, vol. 257, no. 5, p. 1716-1723, D0I:10.1016/J.apsusc.2010.09.003.

[10] Grum, J., Šturm, R. (1997). Laser surface melt-hardening of gray and nodular irons. Applied Surface Science, vol. 109110, p. 128-132, D0I:10.1016/S0169-4332(96)00648-4.

[11] Grum, J., Šturm, R. (1996). Microstructure analysis of nodular iron 400-12 after laser surface melt hardening. Materials Characterization, vol. 37, no. 2-3, p. 81-88, D0l:10.1016/ S1044-5803(96)00063-0.
[12] Gallo, S.C. Alam, N., O'Donnell, R. (2013). In-situ precipitation of TiC upon PTA hardfacing with grey cast iron and titanium for enhanced wear resistance. Surface and Coatings Technology, vol. 214, p. 63-68, D0l:10.1016/j.surfcoat.2012.11.003.

[13] Petru, J., Zlamal, T., Cep, R., Monkova, K., Monka, P. (2013). Influence of cutting parameters on heat-affected zone after laser cutting. Tehnički vjesnik - Technical Gazette, vol. 20, no. 2, p. 225-230.

[14] Šugár, P., Mikoláš, J., Šugárová, J. (2013). Experimental study of Nd:YAG laser machining of Cr-Ni austenitic stainless steel. Tehnički vjesnik - Technical Gazette, vol. 20, no. 4, p. 577580.

[15] Yi, P., Liu, Y.C, Shi, Y.J., Jang, H., Lun, G.D. (2011). Effects analysis of ambient conditions on process of laser surface melting. Optics and Laser Technology, vol. 43, no. 8, p. 14111419, D0l:10.1016/J.optlastec.2011.04.010.

[16] Shi, Y.J., Yi, P., Liu, Y.C. (2011). Numerical investigation of temperature field of different mechanisms in laser forming. Proceedings of the Institution of Mechanical Engineers, Part C: Journal of Mechanical Engineering Science, vol. 226, no. 8, p. 2118-2125, DOl:10.1177/0954406211430884.

[17] Yi, P., Xu, P.Y., Yin, K.P., Li, C.K., Liu, Y.C. (2013). Laser Thermo-Repairing Process Modeling and Thermal Response Analysis on Gray Cast Iron Surface. Chinese Journal of Lasers, vol. 40, no. 3, p. 0303007 (In Chinese), Dol:10.3788/ CJL201340.0303007. 